$41(3) \mid 2012$

Recomposiciones territoriales de las periferias de las metrópolis andinas

\title{
De las luchas urbanas a las grandes inversiones. La nueva urbanidad periférica en Bogotá
}

Des luttes urbaines aux grands investissements. La nouvelle urbanité périphérique à Bogotá

From urban struggles to massive investments: the new peripheral urbanity in Bogota

\section{Alice Beuf}

\section{OpenEdition \\ Journals}

\section{Edición electrónica}

URL: http://journals.openedition.org/bifea/344

DOI: 10.4000/bifea.344

ISSN: 2076-5827

Editor

Institut Français d'Études Andines

\section{Edición impresa}

Fecha de publicación: 31 diciembre 2012

Paginación: 473-501

ISSN: 0303-7495

\section{Referencia electrónica}

Alice Beuf, « De las luchas urbanas a las grandes inversiones. La nueva urbanidad periférica en Bogotá », Bulletin de l'Institut français d'études andines [En línea], 41 (3) | 2012, Publicado el 01 agosto 2013, consultado el 05 noviembre 2020. URL : http://journals.openedition.org/bifea/344 ; DOI : https:// doi.org/10.4000/bifea.344

\section{BY NO ND}

Les contenus du Bulletin de l'Institut français d'études andines sont mis à disposition selon les termes de la licence Creative Commons Attribution - Pas d'Utilisation Commerciale - Pas de Modification 4.0 International. 


\title{
De las luchas urbanas a las grandes inversiones. La nueva urbanidad periférica en Bogotá
}

\author{
Alice Beuf
}

\begin{abstract}
Resumen
El artículo explora las transformaciones recientes de las periferias urbanas de Bogotá. La complejidad creciente de estas nos lleva a plantear el surgimiento de un nuevo modelo de urbanidad periférica. Analizamos este nuevo modelo como el resultado de interacciones entre grandes inversiones recientes de capital, privado pero también público, y las acciones de los habitantes. Para ponerlo en evidencia, restituimos las lógicas históricas de producción de los espacios urbanos en tres zonas de estudio en las periferias occidentales y septentrionales de Bogotá y las enfrentamos con las formas de movilización social y política que se han desarrollado en cada época. La introducción de un modo de producción «desde arriba» en espacios tradicionalmente producidos «desde abajo» conlleva importantes cambios en las formas como los habitantes se relacionan con sus espacios de vida.
\end{abstract}

Palabras clave: periferias urbanas, producción del espacio, Bogotá, urbanidad, sector privado, movilización social

\section{Des luttes urbaines aux grands investissements. La nouvelle urbanité périphérique à Bogotá}

\section{Résumé}

L'article explore les transformations récentes des périphéries urbaines de Bogotá. La complexité croissante de celles-ci nous amène à considérer l'émergence d'un nouveau modèle d'urbanité périphérique. Nous analysons le nouveau modèle d'urbanité périphérique comme le résultat d'interactions entre

* Investigadora del Instituto Francés de Estudios Andinos, sede Bogotá (UMIFRE 17, CNRS-MAE) e investigadora asociada al CREDA (UMR 7227). IFEA, Embajada de Francia: Carrera 11 n. ${ }^{\circ}$ 93-12Bogotá-Colombia. E-mail: alicebeuf@yahoo.fr 
d'importants investissements récents de capitaux, privés mais aussi publics, et les actions des habitants. Pour le mettre en évidence, nous restituons les logiques historiques de production des espaces urbains dans trois zones d'étude des périphéries ouest et nord de Bogotá et nous les confrontons aux formes de mobilisation sociale et politique qui s'y sont développées simultanément. L'introduction d'un mode de production « depuis le haut » dans des espaces traditionnellement produits « par le bas » implique des changements importants dans les façons dont les gens se rapportent à leurs espaces de vie.

Mots clés : périphéries urbaines, production de l'espace, Bogotá, urbanité, secteur privé, mobilisation sociale

\title{
From urban struggles to massive investments: the new peripheral urbanity in Bogota
}

\begin{abstract}
The article explores the recent transformations of the urban peripheries of Bogotá. The increasing complexit of these lead us to consider the emergence of a new model of peripheral urbanity. We analyze the new model of peripheral urbanity as the result of interactions between large recent investment of capital, both from private groups and also from public sector, and the actions of the inhabitants. To examine this theme, we restore the historic logic of production of urban space in three study areas in western and northern peripheries of Bogota and we are faced with forms of social and political mobilization that have evolved simultaneously. The introduction of a mode of production «from above» in spaces traditionally produced «from below» entails significant changes in the ways people relate to their living spaces.
\end{abstract}

Key words: urban peripheries, production of space, Bogota, urbanity, private sector, social mobilization

\section{INTRODUCCIÓN}

Las periferias populares de las metrópolis latinoamericanas nacieron y crecieron como alternativas informales de acceso a la vivienda para los ciudadanos excluidos de los mercados formales. La producción de estos espacios se dio bajo las modalidades de invasiones y fraccionamientos piratas y su consolidación, gracias a las acciones colectivas o individuales de los habitantes, que incluyen luchas urbanas para conseguir que las autoridades invirtieran en materia de servicios domiciliarios y de equipamientos colectivos. Enfatizando la oposición entre ciudad informal y ciudad formal, la teoría de la ciudad dual ha dominado los estudios de las periferias urbanas latinoamericanas durante varias décadas.

Sin embargo, un nuevo modelo de urbanidad periférica está apareciendo hoy en día en las metrópolis latinoamericanas y también, en otras metrópolis del Sur (como en la India por ejemplo). Las investigaciones recientes acerca de las transformaciones de los barrios de origen informal hacen hincapié en fenómenos de incremento de los arriendos (Fix et al., 2003: 18), de verticalización de las casas autoconstruidas (Valladares, 2000) y de construcción de nuevos edificios en altura, 
sean de iniciativa pública o privada, que rompen la horizontalidad de los barrios de origen informal (Saglio-Yatzimirsky, 2002: 212), encontrándose fenómenos de especulación inmobiliaria en ciertos sectores que presentan buena accesibilidad a las redes de transporte y/o a las nuevas centralidades periféricas (Davis, 2006: 89). Por otro lado, la construcción de conjuntos residenciales cerrados en los intersticios libres de los barrios autoconstruidos, para clases altas, medias o bajas (en este último caso, conjuntos residenciales cerrados de vivienda de interés social), contribuye a la profundización de nuevas pautas de microsegregación residencial (Dureau, 2000) y a formas de urbanización insular. Pero, si bien en el caso de los conjuntos cerrados para clases altas, los investigadores documentan modos de vida fragmentados y en rechazo a la sociabilidad urbana tradicional (Capron, 2006; Janoschka, 2002), los habitantes de conjuntos cerrados de menor estatus tienden a reproducir formas de centralidad de un orden más popular. Es así como, «a partir de un hábitat en apariencia controlado en cuanto a sus mecanismos de producción, surge una nueva modalidad de la ciudad informal» (Duhau \& Jacquin, 2008: 185).

Estas evoluciones muestran que las modalidades de producción de las periferias populares están cambiando y se están complejizando, tanto en los barrios de origen informal como en los barrios formales para clases medias bajas y bajas (Abramo, 2003). Si bien las invasiones y los fraccionamientos ilegales siguen en los sectores más marginales, se observa también la llegada a las periferias populares de importantes flujos de capitales, nacionales o globales, que impulsan transformaciones de los sectores más valorizados, más «centrales». Las periferias populares, entendidas como sectores amplios que abarcan tanto barrios de origen informal como barrios formales para clases medias bajas y bajas, se vuelven entonces nuevos espacios de inversión para distintos tipos de actores económicos que apuntan al «potencial de desarrollo» de estos espacios. Dicho en otras palabras, ven allí unos «nichos de negocio» que les permiten expandir su capital y continuar obteniendo ganancias una vez saturados los mercados de las áreas céntricas y de las periferias de mayor estatus. Se trata no solo de las grandes firmas constructoras (de vivienda o de centros comerciales), sino también de la gran distribución, de las cadenas de comercio minorista y, en menor medida, de las empresas de servicios.

Se habla de un «nuevo modelo de urbanidad periférica» en la medida en que estas transformaciones no solo afectan los espacios residenciales sino también las actividades económicas y los espacios públicos. Los paisajes urbanos son radicalmente transformados y la nueva disposición espacial de los elementos urbanos (vivienda, comercio, transporte, espacio público) transforma las relaciones de los habitantes con la ciudad y las formas de apropiación de sus espacios de vida. En este sentido, estas evoluciones marcan una ruptura con las modalidades anteriores de transformación de las periferias populares, pensadas en gran medida a partir del concepto de consolidación o slum upgrading (United Nations Human Settlement Program, 2003: 119), un concepto que se refiere a un cambio gradual hacia una situación mejor (en el marco de una ideología del progreso) y que se da principalmente en los espacios residenciales (mejoras de las viviendas y de los 
servicios domiciliarios). Este concepto de consolidación se hereda del enfoque desarrollado en la década 1990-2000 en el marco de numerosos estudios que enfatizan en las capacidades de los mismos habitantes para la transformación y producción de los espacios urbanos (Berry-Chikhaoui \& Deboulet, 2000).

Contrario a esto, y es la hipótesis de trabajo, el nuevo modelo de urbanidad periférica es el resultado de interacciones entre las recientes grandes inversiones de capital, privado pero también público, y las acciones de los habitantes a largo plazo, es decir, luchas urbanas, movilizaciones colectivas y «esfuerzos personales» de los habitantes (fuerza de trabajo y pequeños aportes de capital) para consolidar la vivienda y/o el barrio. A pesar de sus naturalezas radicalmente opuestas, no se trata de 2 procesos independientes que se dieron uno al lado del otro. Por lo contrario, la realización de las grandes inversiones de capital de estos últimos años tiene como condición de posibilidad, entre otras, las acciones anteriores, individuales y/o colectivas, de los habitantes de los barrios autoconstruidos aledaños. Además, la proximidad de los nuevos espacios de inversión tiene impactos en distintos ámbitos al interior mismo de los barrios autoconstruidos y redefine las prácticas espaciales de sus habitantes.

Se propone aquí entonces, analizar la construcción de este nuevo modelo de urbanidad periférica. Para tal propósito, se utilizará entrevistas con diferentes actores, del sector privado, de las organizaciones sociales y de habitantes, realizadas en el marco de un trabajo de campo en 3 zonas de la periferia occidental y noroccidental de Bogotá, que agrupan decenas de barrios y que se denominan Suba-Pueblo, Patio Bonito/Tintal y Norte. Las 3 zonas de estudio corresponden a importantes áreas de expansión de la ciudad, que se fueron densificando desde los años 1990 hasta alcanzar hoy en día en algunos sectores más de 500 habitantes por hectárea (fig. 1). Suba-Pueblo (582 000 habitantes en 2005) presenta una cierta unidad espacial debido a su configuración topográfica (ya que se encuentra aislado del resto de la localidad de Suba por la colina de la Conejera y el humedal Juan Amarillo) y a su condición de antiguo municipio anexado por Bogotá en 1954. Patio Bonito-Tintal (338 000 habitantes en 2005) corresponde a los barrios de la localidad de Kennedy ubicados al oeste de la avenida Ciudad de Cali, un sector que, a pesar de su división entre la parte más antigua de origen informal correspondiente a Patio Bonito y la parte recientemente desarrollada que es la del Tintal, es indistintamente identificado por los habitantes. Finalmente, la zona Norte (144 000 habitantes en 2005) la conforman las urbanizaciones que se desarrollaron a lo largo de una de las principales entradas de la ciudad, la autopista Norte. No cuenta verdaderamente con una unidad de la zona, a diferencia de Suba-Pueblo y Patio Bonito-Tintal.

\section{LA PRODUCCIÓN DE LAS PERIFERIAS POPULARES: UNA HISTORIA JALONADA DE LUCHAS URBANAS}

Las periferias occidentales y noroccidentales de Bogotá se caracterizan, hoy en día, por una microsegregación socioespacial bastante intensa que se evidencia 
De las luchas urbanas a las grandes inversiones. La nueva urbanidad periférica en Bogotá

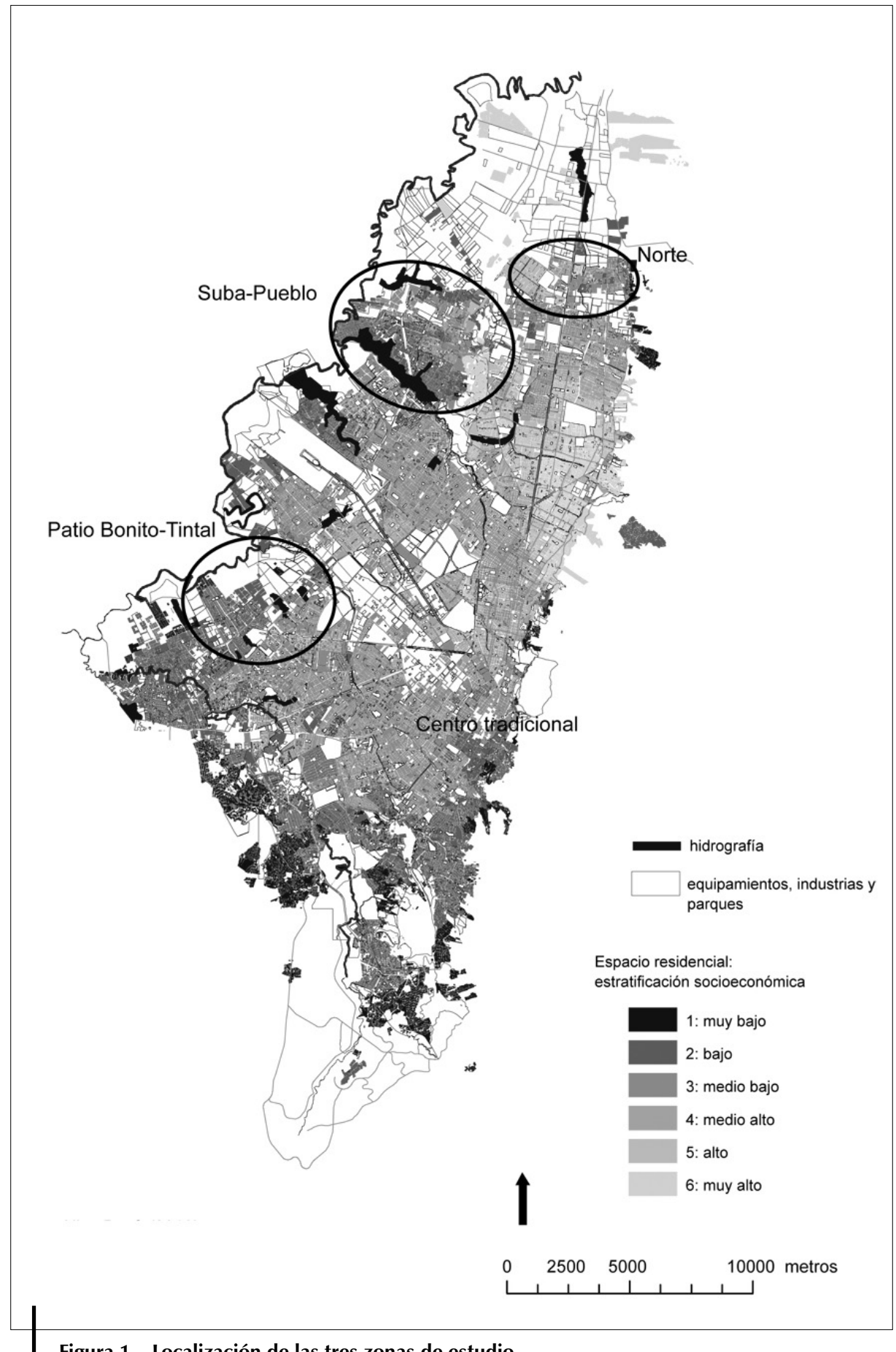

Figura 1 - Localización de las tres zonas de estudio 
a nivel morfológico en la imbricación de conjuntos residenciales cerrados «formales»1 (ya sean de vivienda de interés social o no) en los intersticios de los barrios autoconstruidos más o menos consolidados. Poblaciones de clase media baja y de clase baja habitan estos barrios periféricos, en los cuales viven también, de manera puntual, poblaciones de clase media alta y en las márgenes, poblaciones de clase baja-baja. Esta configuración socioespacial es el resultado de la complejidad de los procesos de producción de estos espacios. En esta primera parte, restituimos las etapas de estos procesos históricos haciendo énfasis en las acciones de los habitantes.

\section{1. El protagonismo de los habitantes en la urbanización informal de las periferias}

En Bogotá, la gran ola de urbanización informal inició en los años 1950, correspondientes a la primera fase de la transición urbana y a una época de violencia en el campo que agudizó el éxodo rural. En estos años, la tasa de crecimiento urbano era una de las más altas en el mundo, superando el $7 \%$ anual. El proceso de expansión urbana cambió de ritmo y escala, masificándose en relación con el periodo anterior, en el cual la expansión urbana incipiente se daba bajo la forma de urbanizaciones discontinuas en el altiplano de la Sabana de Bogotá (años 1920-1950). Los espacios correspondientes a las actuales periferias occidentales y noroccidentales estaban constituidos hasta los años 1950 por grandes propiedades, antiguas haciendas que se extendían entre humedales y pastizales. La única parte urbanizada era el casco urbano del antiguo municipio de Suba: algunas manzanas construidas alrededor de la plaza fundacional. Estas estructuras prediales agrarias formaron la base del proceso de urbanización de Bogotá, formal como informal.

En la producción del espacio urbano bogotano, las urbanizaciones o fraccionamientos «piratas» han tenido mucho más importancia que las invasiones. Esta modalidad de urbanización es informal porque no respeta la normatividad urbana, pero a diferencia del caso de las invasiones, existe una transacción mercantil. El urbanizador «pirata», que actúa como un verdadero agente capitalista en búsqueda de la más alta rentabilidad de sus inversiones, compra los terrenos a hacendados o a campesinos a precio agrícola, los lotea, dota con un mínimo de equipamiento y vende los lotes (a un precio total mucho mayor a su inversión) a pobladores individuales que recurren a la autoconstrucción para desarrollar sus viviendas de manera progresiva (Jaramillo, 2008). Esta modalidad informal de producción del espacio urbano ha sido investigada de manera extensa, en particular en cuanto a las relaciones sociales que contribuye a crear en las periferias populares: relaciones de paternalismo entre urbanizadores y compradores que

1 Hoy en día en Bogotá, casi la totalidad de la oferta de vivienda nueva formal se da bajo diversas modalidades de urbanismo cerrado: conjuntos residenciales cerrados (todos los estratos) o edificios de alta seguridad, exclusivamente para los estratos altos (4, 5 y 6). 
muy a menudo se transformaban en clientelismo político, procesos organizativos de los habitantes para equipar los barrios. En efecto, los pobladores de un mismo fraccionamiento llegaban más o menos al mismo tiempo y tras su instalación necesitaban conseguir los servicios y equipamientos colectivos que hacían falta. Estos procesos organizativos impulsaron luchas urbanas lideradas en general por las Juntas de Acción Comunal (JAC), que son en Bogotá organizaciones comunitarias de carácter barrial creadas por las autoridades desde 1958. En este sentido, los habitantes tuvieron un protagonismo importante en la primera etapa de producción de las periferias populares, tanto por sus acciones individuales (construcción de las viviendas) como por sus acciones colectivas mediante las luchas por el equipamiento, la legalización y más allá, el reconocimiento de los nuevos barrios. En eso, coincidimos con Franck Poupeau que afirma en este mismo número temático que «el acceso a la propiedad y a los servicios es el primer momento del acceso a la existencia social y al reconocimiento político». Veamos ejemplos de ello en las zonas de estudio.

En Suba, la primera gran ola de urbanización informal se dio en el sector del Rincón de Suba, ubicado para la época en las afueras del núcleo municipal de Suba. Alcanzó su nivel máximo en los años 1970, con 30 desarrollos de 168 hectáreas (Ordoñez Montoya, 1992). El desarrollo del Rincón de Suba fue impulsado por un lado, por la apropiación de las tierras de los indígenas Muiscas² por grandes empresas de cultivo de flores que vendieron luego una parte de sus predios a urbanizadores piratas 3 y por otro lado, por la consolidación de la centralidad popular del barrio Quiroga, ubicada al otro lado del humedal Juan Amarillo. Esta oferta cercana de bienes y servicios atrajo nuevos pobladores en este sector aislado. Sin embargo, el atractivo principal para los que llegaron en las décadas de 1960-1980, procedentes en su gran mayoría de regiones rurales cercanas a Bogotá (Boyacá, Cundinamarca, Tolima, Santanderes), era la facilidad de conseguir un lote. Una vez propietarios de su lote, tuvieron que solucionar prontamente necesidades colectivas básicas. Un primer motivo de organización fue la provisión de agua, ya que no existía acueducto. Mediante la colecta de dinero dentro de la misma comunidad (bazares, rifas, etc.) se pudo construir pilas de agua. Solamente en un segundo momento, en 1974, la Junta de Acción Comunal consiguió la instalación del servicio por parte de la Empresa de Acueducto y Alcantarillado de Bogotá, pero tuvo que presionar al alcalde para lograr una rebaja en la tarifa que inicialmente era muy alta. De la misma manera, los habitantes organizados aportaron el dinero para comprar e instalar cables de energía y conectar la comunidad a la red eléctrica. Otras acciones destacadas financiadas y realizadas por los mismos habitantes fueron las construcciones del salón comunal, de la casa cultural y de la iglesia. Una lucha emblemática en el Rincón de Suba fue la manera como pequeños comerciantes organizados consiguieron un lote y edificaron la plaza de mercado: se volvieron los dueños de esta plaza, que desde luego ha

\footnotetext{
2 Comunidad indígena históricamente establecida en el pueblo de Suba y en toda la Sabana de Bogotá.

3 En este sector, los principales urbanizadores piratas fueron Bulla, Caviativa, Yopasa y Almonacid.
} 
mantenido un fuerte dinamismo. Sin embargo, fueron reubicados por la alcaldía a inicios de 2000, en un lote que nunca usaron porque no les pareció favorable al comercio. Dejaron vacío un edificio grande con locales y prefirieron instalarse en la calle. Hoy en día, la plaza de mercado del Rincón de Suba corresponde a una porción de calle, en la cual se ubican cada día entre 120 y 200 puestos de venta de productos alimenticios (entrevista a José Miguel Barajas, presidente de la Junta de Acción Comunal de Rincón-Escuela y resultado del trabajo de campo en la zona). Esta calle está apropiada de hecho por los comerciantes, que siguen siendo dueños de parte de un edificio sin uso por ahora. Si bien existen conflictos, no han podido ser expulsados de su sitio de trabajo: por esta historia colectiva, los comerciantes se han ganado una legitimidad importante dentro del barrio e incluso, dentro de la localidad.

El inicio de la urbanización de Patio Bonito se dio cuando, en 1974, el terrateniente José Zamullo dividió de forma «pirata» las tierras de su hacienda «Los Pantanos» y empezó una gran operación vendiendo simultáneamente 1050 parcelas de $6 \times 12 \mathrm{~m}$, con título de propiedad pero sin servicios urbanos. La primera etapa de Patio Bonito se vendió exitosamente en un mes al precio de 13000 pesos la parcela, lo cual llevó al urbanizador pirata a comercializar una segunda etapa de la misma amplitud, vendida a 36000 pesos la parcela. Los nuevos habitantes se sintieron atraídos por la proximidad a la central de abastos Corabastos que, desde su inauguración en 1972, creó un gran número de empleos. Cerca de la mitad de los primeros habitantes de Patio Bonito trabajaban en Corabastos. Para Manuel Díaz, fundador de Patio Bonito, los primeros habitantes del barrio tuvieron un papel protagónico en la construcción y equipamiento del barrio. Reproducimos a continuación su relato sobre estos años de lucha:

«Todo lo que se ve en Patio Bonito, es el resultado de la JAC y de las luchas urbanas: el transporte, el alumbrado público, el colegio distrital, que antes era una escuela que habíamos construido en las instalaciones del gallinero de la hacienda Los Pantanos. Al principio logramos construir cinco salones de clase que recibían a los alumnos sin ni siquiera tener fosa séptica. Fue solamente en 1978 que la Secretaría de Educación oficializó la escuela. Para la red de alcantarillado, teníamos un plan 30/70: la comunidad debía adelantar $30 \%$ de los costos. Lo mismo pasó con la red de agua potable que en un principio provenía de un tubo clandestino conectado a la red a nivel de Banderas (Kennedy Central) y por culpa del cual había conflictos permanentes con los otros barrios informales del sector. En esa época, la avenida Ciudad de Cali era un sanjón y la Calle 38 Sur un canal que servía para irrigar las tierras de la hacienda. Nos tocó luchar contra los dueños de las tierras para que las aguas del alcantarillado se descargaran en ese canal y ganamos esa pelea. Fue todo un símbolo. En 1977 quitaron los alambres de púas de la hacienda y declararon vía pública el canal de la 38. La 38 Sur se convirtió en la calle principal de Patio Bonito. El desarrollo llegó cuando los habitantes se unieron para obtener todos esos elementos. Inclusive construimos las iglesias del barrio organizándonos. Los años 19741979 fueron una etapa crucial. En octubre de 1979 hubo una inundación 
por una ruptura de los diques del río Bogotá, del que no se hacían cargo las autoridades. La crecida duró más de un mes y el 90 \% de los habitantes del barrio tuvo que dejar sus casas. Nos organizamos en comités cuando el agua empezó a subir para tratar de contenerla. En esa época teníamos una gran capacidad de movilización: reunimos 5000 personas para controlar la crecida y luego secar las calles del barrio. El gobierno no hizo nada, nos dejó solos, claro que con la ayuda de la Cruz Roja, de los bomberos y de la empresa de acueducto. Solo pudimos volver a nuestras casas en 1980. La inundación se dio porque el río estaba a un nivel más alto que el del barrio: las autoridades no hicieron nada porque no querían que el sector se urbanizara, querían reservar los terrenos para el basurero municipal, que de todas maneras nos pusieron en 1980 en el sector de Gibraltar detrás del actual Terminal de Transmilenio (Las Américas). Pero logramos sacarlo en 1988 después de otras luchas urbanas. En esa época empezamos también a pagar la construcción de la avenida Ciudad de Cali (con el impuesto de contribución por valorización4) pues su construcción debía beneficiar a la ciudad y al sector. Entonces, el equipamiento del barrio fue financiado en gran parte por la comunidad. Hoy, hay un cambio de perspectiva y las inversiones sociales aumentaron en el sector. La movilización comunitaria no tiene el mismo eco que antes, así haya ahora 50 JAC en el sector de Patio Bonito. Y yo fundé la primera. Patio Bonito es un ejemplo de luchas sociales en la ciudad. No permitimos que el gran capital nos sacara de aquí. Nos quedamos. Ahora los grandes proyectos inmobiliarios y comerciales nos rodean y aprovechan el mejoramiento del sector por el que luchamos tanto durante todos estos años».

En el Norte, las urbanizaciones informales empezaron igualmente en los años 1960 con la fundación del barrio El Codito que se inició como una invasión de terrenos, motivada por la proximidad a las canteras de arena. Así como lo relató el presidente de la JAC, los habitantes de los nuevos barrios se organizaron luego para obtener progresivamente, a través de sus luchas, los servicios públicos (agua, electricidad, alcantarillado) y los equipamientos e infraestructuras de base (calles y escuelas).

A partir de 1980, mientras continuaba la urbanización informal de esos sectores periféricos, se dieron las primeras legalizaciones de los barrios en proceso de consolidación, como por ejemplo El Codito en 1985.

\section{2. Las primeras urbanizaciones formales en las periferias populares y la transformación de las luchas urbanas}

En la década de 1990, los primeros proyectos inmobiliarios formales aparecieron en ciertas periferias populares de Bogotá. Varios factores contribuyeron a estas

4 La Contribución por Valorización es en Colombia un impuesto sobre las propiedades raíces que se beneficien con la ejecución de obras de interés público local, reglamentada por el Decreto 0604 de 1966. 
transformaciones paulatinas, que se intensificaron luego, a inicio de 2000, como lo se verá en adelante. Debido a su consolidación y legalización, los barrios autoconstruidos ganaron reconocimiento social y mejoraron su «imagen» para las clases medias bajas, más dispuestas a vivir cerca de ellos. Veamos como se pusieron en marcha a nivel local estas nuevas modalidades de producción de las periferias populares.

Si Manuel Díaz hablaba de grandes proyectos inmobiliarios es porque los vastos terrenos de la periferia occidental de la ciudad suscitaban el apetito de las grandes constructoras desde la mitad del siglo XX. Las altas tasas de crecimiento demográfico de la ciudad no dejaban dudas de que un día se iban a urbanizar. Así, en el Acuerdo 9 de 1990, las zonas ubicadas al oeste del núcleo municipal de Suba (Tibabuyes) y de Patio Bonito (Tintal-Central) así como la parte norte de este sector (Tintal-Norte) fueron declaradas grandes zonas de expansión de la ciudad, destinadas prioritariamente a la vivienda social 5 . Posteriormente, en 1994, con el «Plan de Ordenamiento Físico del Sistema Hídrico y Borde Occidental de Bogotá» se especificó el estatus de estos espacios y se confirmó dicha normatividad que se mantuvo hasta el POT. En la zona Norte, en cambio, se urbanizaron los alrededores de la Autopista a medida que se vendieron las parcelas privadas. En esta área de la ciudad, el proceso de urbanización fue tanto formal (San José de Bavaria en los terrenos de la cervecería Bavaria) como informal. Más recientemente, se dio bajo la forma de conjuntos residenciales cerrados para las clases medias bajas. Sin embargo, desde finales de 1990, se debatió el proyecto de Plan Zonal del Norte, para urbanizar de manera integral todos los terrenos al norte del perímetro urbano. Este finalmente fue aprobado en 2010.

En Suba, los inversionistas privados impulsaron la nueva dinámica después de la construcción a mediados de los años 1990 de la avenida Suba6. Dos cajas de compensación familiar lanzaron allí los primeros grandes proyectos de vivienda social al oeste de este sector, la primera Ciudadela CAFAM y el proyecto Suba Compartir. Este último tenía 5 etapas para un total de 4200 apartamentos. Entraba en discontinuidad con la urbanización existente porque en muchos terrenos suburbanos, los cultivos de flores, que rodean Suba, seguían siendo más rentables que los proyectos de vivienda de interés social. De esta manera, empezaron a llegar a Suba nuevas poblaciones de un estatus social superior al de los habitantes de los barrios autoconstruidos. Según Miguel Tellez, consultor y responsable del estudio de mercado de la primera Ciudadela CAFAM de Suba, la motivación principal de los recién llegados fue la posibilidad de comprar una vivienda a un precio relativamente bajo, frente a los demás proyectos de vivienda formal, en un sector que, así sea periférico, está en el norte de la ciudad. Muchas familias buscaban esta ubicación porque querían escolarizar a sus hijos en uno de los colegios privados del norte de la ciudad y disminuir así el tiempo de transporte de

5 Cf. El Tiempo, «El futuro de Bogotá está en el occidente», 20 de agosto de 1994. Cabe aclarar que estas zonas tuvieron una urbanización principalmente de «tope VIS», que es la categoría de vivienda social más cara e inasequible para los pobres.

6 Cf. El Tiempo, «Suba, un sector que se valoriza», 4 de marzo de 1995. 
los niños. Simultáneamente a la construcción de esos proyectos inmobiliarios que rompieron con las escalas de intervención anteriores en ese sector de la ciudad, fue inaugurado en 1995 el centro comercial Centro Suba, reforzando la vocación comercial del cruce estratégico de la avenida Suba con la calle 91 (la segunda vía de acceso a Suba), en donde se había implantado en 1990 el centro comercial Subazar, de menor dimensión.

Al contrario de Suba, en donde la urbanización fue impulsada exclusivamente por la iniciativa privada, el Tintal 7 fue objeto de un verdadero plan de urbanización integral, famoso por haber sido la primera experiencia de concertación exitosa entre los terratenientes, la administración distrital y las empresas de servicios públicos (Acueducto de Bogotá), con el fin de desarrollar de manera formal terrenos periféricos y construir vivienda de interés social. Según un modelo ahora prohibido por la adopción del principio de distribución equitativa de las cargas y beneficios de la urbanización, el distrito se comprometió a financiar la urbanización de terrenos para que los dueños de estos los desarrollaran y obtuvieran todos los beneficios. Como consecuencia del acto final de concertación del 16 de diciembre de 1992, el Decreto 012 de 1993 reglamentó la urbanización futura del sector: este sector, llamado en aquella época Tintal Central, comprendía 740 hectáreas, que compartían 7 propietarios. Era un vasto perímetro, correspondiente a las UPZ actuales de Patio Bonito (82), Las Margaritas (83) y Calandaima (79), que rodeaba los barrios autoconstruidos consolidados alrededor de la urbanización de Patio Bonito. Además del Tintal Central, se habían definido 2 perímetros más, el Tintal Norte (UPZ 78) y el Tintal Sur en la localidad de Bosa, que representaban 471 hectáreas en manos de 24 propietarios. Inicialmente se había previsto que el conjunto de terrenos de los Tintales Central, Norte y Sur pudieran recibir a 350000 personas8. Como en el caso de Suba, el desarrollo de la zona del Tintal se pensó simultáneamente a la planeación de la construcción de una vía arteria, la avenida Ciudad de Cali, pavimentada y habilitada completamente al final de los años 1990. Sin embargo, la urbanización del Tintal Central fue obstaculizada por la invasión de terrenos al oeste de Patio Bonito, en proximidad al río Bogotá, en terrenos que corresponden a los barrios actuales de Dindalito y Las Almendras. En consecuencia no se pudieron cumplir las previsiones iniciales, pero se llevaron a cabo importantes proyectos inmobiliarios esencialmente en el perímetro de la UPZ Calandaima (fig. 2).

Con la masificación de la producción de las periferias populares, nuevas formas de movilización social y política aparecieron. Los que llegaron a vivir en los grandes conjuntos de viviendas, tuvieron una relación necesariamente más pasiva e individualista con la construcción de sus barrios. Llegaron a habitar casas ya terminadas, con los servicios básicos. Sin embargo, se formaron generalmente JAC

7 En este artículo, se utiliza el término de «Tintal» para designar el perímetro de la UPZ Calandaima, ya que los habitantes y autoridades lo identifican ahora de esta manera (nombre de los equipamientos y estaciones de bus). No corresponde exactamente al perímetro de expansión urbano llamado «Tintal» a inicios de 1990.

8 Cf. El Tiempo, «Tintal, polo de desarrollo urbano», 10 de septiembre de 1994. 


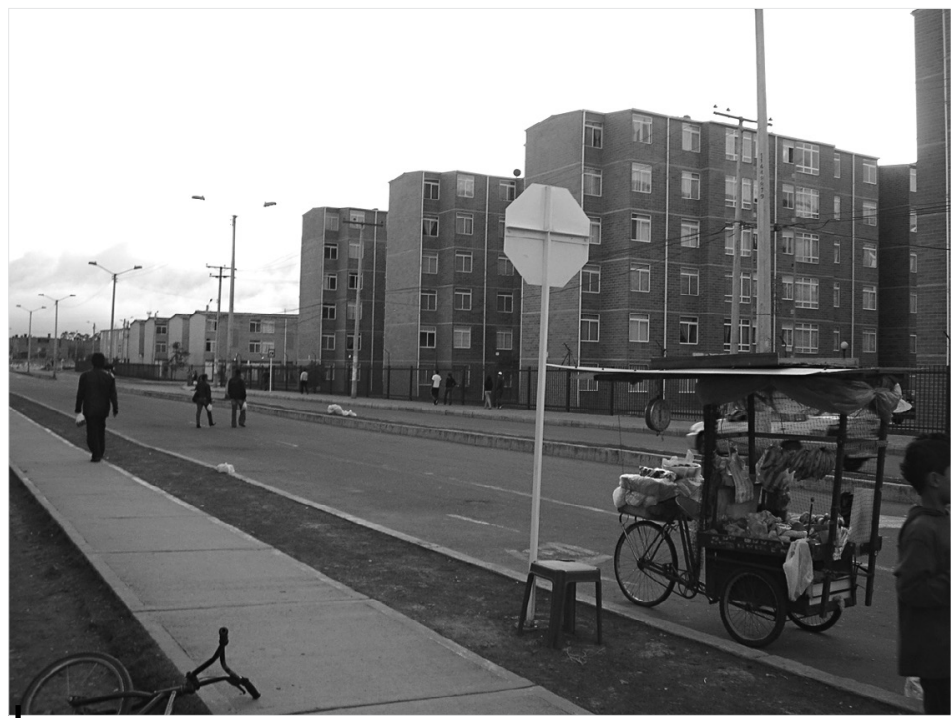

Figura 2 - Conjuntos residenciales cerrados de vivienda de interés social en el Tintal: una alternancia de conjuntos de edificios de apartamentos de 6 pisos y casas adosadas de 3 pisos pero $3 \mathrm{~m}$ de ancho

Foto: Alice Beuf (2009)

a nivel de cada conjunto y en el marco de estas, los nuevos habitantes a veces se movilizaron para resolver problemas de transporte (cuando los nuevos conjuntos resultaban muy alejados de las rutas o cuando las vías de los barrios estaban en muy mal estado), de equipamiento colectivo (colegios) y de abastecimiento (organización de mercados informales en lotes no urbanizados cuando resultaban muy alejados de los comercios existentes). En este sentido, en las situaciones en las cuales se siente la ausencia del Estado, el carácter formal de las viviendas no constituye una garantía de reconocimiento social y político y actividades de naturaleza informal aparecen en los barrios formales (Duhau \& Jacquin, 2008).

En Bogotá, historia común, libro publicado en 1998 y firmado por Jorge Orjuela hace hincapié en este aspecto. Titulado «El Compartir Suba que el Distrito desconoce», muestra que si bien «todo el mundo sabe dónde queda este barrio (los policías, los educadores, los sacerdotes, los taxistas, etc.), no figura en la cartografía distrital ni tampoco en los planes de desarrollo local». La historia de la formación del Compartir Suba como barrio, es decir como unidad socioterritorial una vez habitado el proyecto inmobiliario, es reveladora de las transformaciones de las luchas por el reconocimiento llevadas a cabo en estos nuevos barrios populares, de un estrato ligeramente superior a los barrios de autoconstrucción. En el caso de Suba Compartir, el reconocimiento social y político se logró en buena parte gracias a un nuevo tipo de lucha: la lucha ambiental. En efecto, ubicado al borde del perímetro urbano de Bogotá, el conjunto residencial colinda con el humedal de La Conejera. Cuando llegaron en 1991 los habitantes de la primera etapa del proyecto, este humedal era totalmente desconocido, tanto por los habitantes, 
como por las empresas constructoras y las autoridades, que todavía no tenían mucho interés por las cuestiones ambientales. Los habitantes vieron entonces cómo las volquetas utilizadas para la construcción de la segunda etapa del proyecto descargaban los escombros dentro del humedal. Pero también observaban en el humedal aves raras, que a veces venían hasta sus casas. Este espectáculo cotidiano dio el impulso para la organización de los nuevos propietarios en torno a la defensa del humedal y también para la formación de líderes ambientalistas (entrevista a Julieta Jiménez Vásquez, miembro de la JAC Suba Compartir, 2009). Se formó en 1993 la Fundación Humedal La Conejera que agrupaba a habitantes del conjunto Compartir Suba, así como a estudiantes y diversos ecólogos. Desde luego, esta fundación, una de las primeras de ese tipo en Bogotá, tuvo un papel clave en el rumbo que tomó la urbanización del noroccidente de la ciudad. Así, el proyecto de construcción de un anillo vial perimetral, previsto desde 1998, fue parado por razones ambientales gracias a la movilización ciudadana. Cabe mencionar, sin embargo, que este conflicto territorial se inscribía en un debate más amplio acerca del Plan Zonal del Norte y que a inicios de 2000, el Ministerio de Ambiente dio razón a los ambientalistas al quitar del perímetro urbanizable unas 2000 hectáreas que el alcalde de la época, Enrique Peñalosa, quería urbanizar (Ardila, 2003).

Aunque el movimiento comunal haya perdido fuerza con la masificación de la producción de vivienda social, las luchas urbanas de los habitantes para mejorar sus condiciones materiales de vida y conseguir un reconocimiento social y político no desaparecieron. Por una parte, la política de participación del distrito desde inicios de 1990 permite canalizar una parte de las reivindicaciones de carácter microlocal. Las JAC y otras organizaciones sociales que se van conformando a nivel barrial y zonal pueden ahora interactuar en los espacios formales de participación como los Consejos Locales de Planeación o presentar sus propuestas ante los Encuentros Ciudadanos, que constituyen la primera etapa de «diagnóstico» de los procesos de formulación de los Planes de Desarrollo de cada localidad. Si bien la capacidad real de influir sobre la toma de decisión en el marco de estos procesos participativos ha sido puesta en tela de juicio, el reconocimiento formal de sus voces lleva a los habitantes a buscar el diálogo con la administración. Por otra parte, en el caso de los barrios formales recientes, que casi siempre son conjuntos residenciales cerrados, incluso de viviendas de interés social o prioritario, las movilizaciones sociales están condicionadas por el régimen de Propiedad Horizontal, que modifica sus mecanismos y alcances.

Tanto la política de promoción de la participación ciudadana como las transformaciones de las modalidades de producción de los espacios urbanos, y por ende de su apropiación ciudadana, modificaron radicalmente las formas de movilización social. Los objetivos y las escalas de acción se han diversificado también, al incorporar por ejemplo las cuestiones de justicia ambiental. 


\section{3. Los elementos del nuevo modelo de urbanidad periférica}

Estas periferias en expansión conocieron cambios importantes a principios de 2000 con la inauguración, en 2001, de la Biblioteca El Tintal, una de las tres principales bibliotecas de Bogotá. Luego la llegada del transporte público Transmilenio permitió mejorar la accesibilidad y disminuir los tiempos de los trayectos hacia el centro metropolitano. También permitió habilitar los espacios públicos y ordenar los paisajes urbanos. En el año 2001 se puso en servicio el Portal Norte, luego en 2004 el Portal de Las Américas, ubicado en el Tintal y en 2006, el Portal de Suba. Estas transformaciones físicas contribuyeron además a revertir las representaciones basadas en el carácter popular de estos territorios.

El crecimiento de los espacios residenciales y las mejoras en términos de movilidad favorecieron la aparición de una nueva generación de centros comerciales. La transformación de las condiciones de accesibilidad gracias a la puesta en servicio del sistema de transporte masivo Transmilenio y la consecuente concentración de los flujos de personas (peatones y automovilistas) en unos nodos de movilidad (los portales de Transmilenio), permitió el cambio de escala de los establecimientos comerciales y la transformación de los paisajes urbanos (fig. 3). Cerca del Portal Norte, el centro comercial Santafé, inaugurado en 2006, es actualmente el segundo centro comercial más grande de Colombia y acoge un gran número de almacenes de marca internacional (500 locales comerciales). En Suba-Pueblo y Patio Bonito-Tintal,

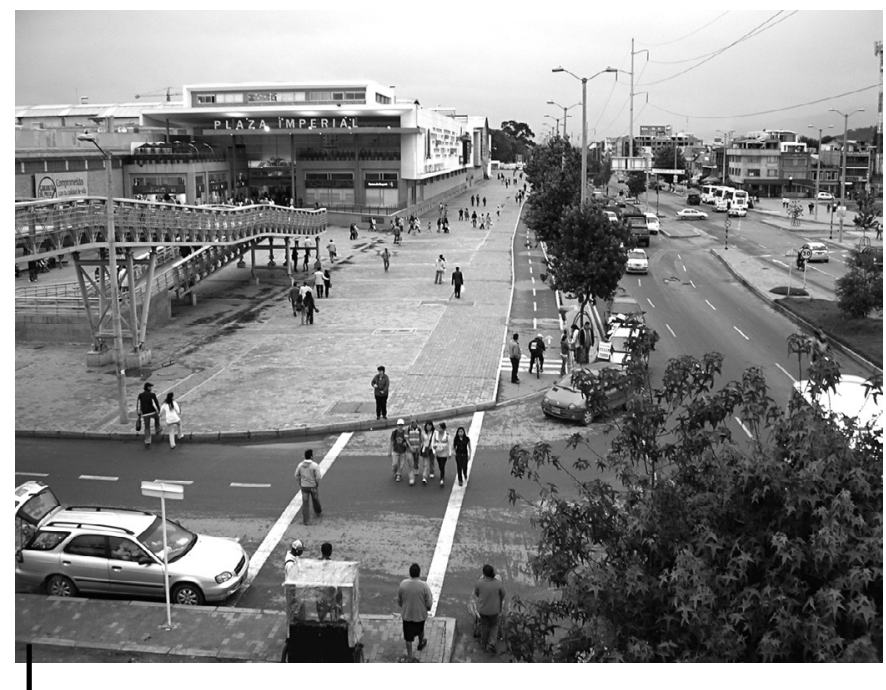

Figura 3 - El centro comercial Plaza Milenio y los espacios públicos construidos simultáneamente al Transmilenio: un cambio de escala arquitectónico que ha transformado los paisajes urbanos y las prácticas socioespaciales de Suba

El portal de Suba de Transmilenio está justo a la derecha del marco de la fotografía

Foto: Alice Beuf (2009) 
de nivel socioeconómico inferior, los centros comerciales Plaza Imperial (287 locales comerciales), Tintal Plaza (203 locales comerciales) y Plaza Milenio (150 locales comerciales) tienen estándares casi similares a los centros comerciales de los barrios ricos del norte de la ciudad. Empresas multinacionales como Carrefour, Falabella o Sodimac son los almacenes-anclas de esos centros comerciales. En palabras de Miguel Téllez, estos centros comerciales «tienen los mismos almacenes, la misma arquitectura y los parqueaderos igual de llenos» que los del norte. El nuevo modelo de urbanidad periférica conduce así a una recomposición de la centralidad en los espacios periféricos siendo la implantación de grandes centros comerciales, con presencia de inversiones extranjeras directas (a diferencia de los pequeños centros comerciales en el periodo anterior), un elemento fundamental del nuevo modelo, en el cual, y en una escala sin precedentes hasta entonces en las periferias, los centros comerciales de segunda generación aglomeran grandes tiendas especializadas que conducen a la formación de nuevos sectores centrales.

Los desarrollos comerciales contribuyen a una valorización espacialmente diferenciada de los precios del suelo, con la aparición de nuevas rentas de localización en función de la distancia a los centros comerciales. Hoy en día la oferta de vivienda en esas periferias no se limita a la vivienda social para los estratos 2 y 3; además de ello, a proximidad a los centros comerciales Plaza Imperial y Tintal, se ven nuevos edificios de 12 pisos que ofrecen viviendas de buen nivel, en estrato 4, destinadas a familias con ingresos de más de 4,5 millones de pesos (2 000 euros), o sea cerca de 8 veces el salario mínimo que en 2012 era de 566000 pesos. Estas cifras corresponden a los resultados de la encuesta de campo realizada en las zonas de estudio en 2009 y durante la cual se pidió diferentes cotizaciones para compra de apartamentos dentro de los proyectos inmobiliarios en proceso de comercialización.

Simultáneamente a estas evoluciones alrededor de los portales de Transmilenio y de los nuevos centros comerciales, los barrios de origen informal, hoy legalizados y consolidados, tuvieron transformaciones importantes por la densificación de los espacios construidos (construcción de 3 o inclusive 4 pisos en las casas de desarrollo progresivo), por la realización de inversiones del distrito en el marco de programas de mejoramiento integral de barrios y por el dinamismo de sus actividades económicas. Este dinamismo se observa en particular en los lugares conocidos como centralidades populares (fig. 4), que definimos como «concentraciones de servicios y de pequeños y medianos establecimientos comerciales que polarizan un conjunto de barrios y que son identificados con un nombre por los habitantes» (Beuf, 2011).

Las periferias occidentales y noroccidentales de Bogotá, de crecimiento rápido, se caracterizan hoy en día por una gran complejidad espacial, de la cual emerge lo que se ha llamado una nueva urbanidad periférica. Nuevas modalidades de producción han transformado la cara de estos espacios, caracterizados exclusivamente hasta hace 20 años por una adición de barrios informales. La masificación de producción de la vivienda social y la multiplicación de comercios y lugares de consumo cambiaron la relación de los habitantes con sus espacios de vida. El crecimiento 


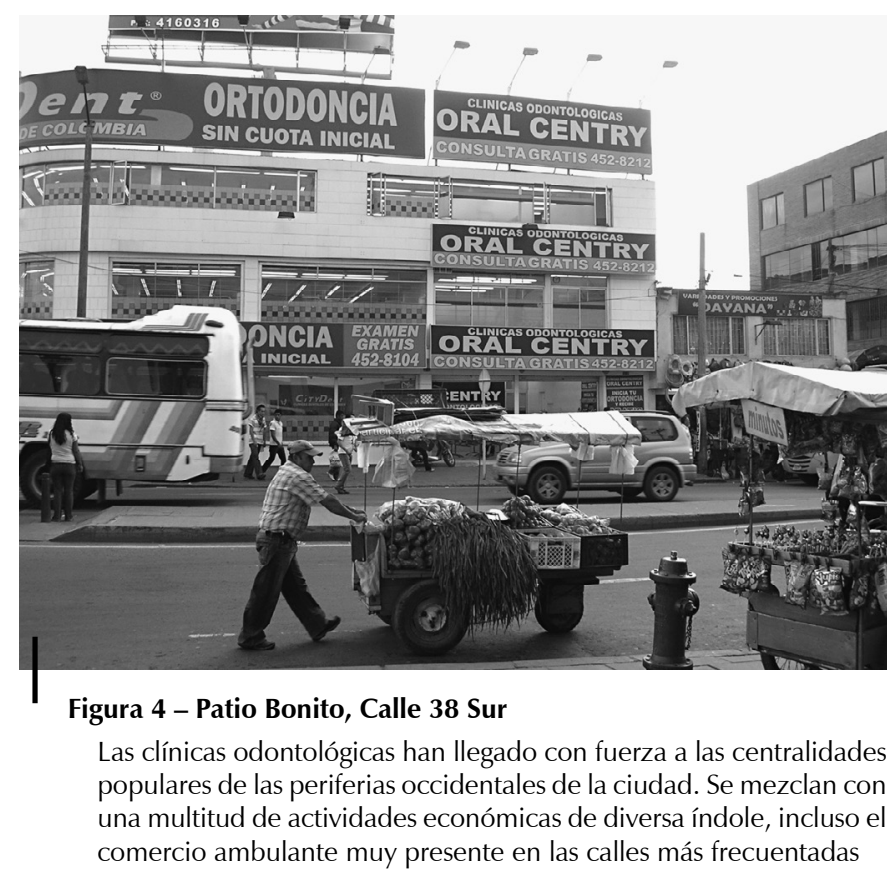

Foto: Alice Beuf (2009)

demográfico y las consecuentes recomposiciones sociales de los barrios favorecen el anonimato urbano y sus corolarios bien conocidos de los sociólogos urbanos: individualismo, anomía. Las referencias identitarias y territoriales cambian; cada vez más personas proyectan sus vidas cotidianas a la escala de territorios amplios que pueden abarcar un conjunto de barrios o una zona extendida en torno a las nuevas centralidades periféricas en formación, que se ha definido como los sistemas de lugares (Beuf, 2011) que articulan nuevos sectores centrales en torno a los centros comerciales de última generación, centralidades populares y centralidades más antiguas (núcleos fundacionales de los municipios anexados por ejemplo). También existen muchas interacciones con otras partes de la ciudad donde se ubican empleos y recursos urbanos. Esta redefinición de las escalas de territorialidad de los individuos va de la mano con la aparición de nuevas formas de movilización social y política que no tienen el barrio como único referente. Se observan por ejemplo, grupos juveniles que hacen trabajo social y político a la escala de un conjunto de barrios, de parte o de toda una localidad, asociaciones ambientales que articulan problemáticas locales, específicas a ciertos barrios, con desafíos planteados a nivel distrital o regional, etc. También existen procesos de unión de diversas JAC para plantear problemáticas locales a un nivel superior al barrio (ejemplo de la asociación de una decena de JAC del sector del Rincón de Suba). Sin embargo, como se ha podido mostrar en otro lugar, persisten formas de territorialidades y de movilizaciones sociales y políticas más tradicionales que siguen teniendo el barrio como referencia principal (Beuf, 2011). 
El nuevo modelo de urbanidad periférica puede interpretarse entonces como el resultado de la yuxtaposición de una pluralidad de modalidades de producción de los espacios periféricos que genera nuevas identidades y prácticas urbanas que cohabitan e interactúan con identidades y prácticas más antiguas, relacionadas con los primeros momentos de formación de los barrios periféricos. Además, este nuevo modelo de urbanidad periférica es productor de desigualdades al interior mismo de las periferias populares, que ya no son tan homogéneas como antes. Por lo tanto, las formas de segregación socioespacial a escala micro se están redefiniendo, entre unos espacios que se volvieron centrales dentro de las periferias populares y otros espacios cuya marginalidad se reproduce en relación a los nuevos espacios centrales de las mismas periferias.

Este nuevo modelo de urbanidad periférica tiene sus lógicas, allí no vemos procesos espontáneos cuya complejidad no se podría explicar. Prueba de ello es que no se observa con tanta claridad en las periferias sur de Bogotá. En efecto, las periferias sur son más pobres, más homogéneas y objetos de representaciones más difíciles de revertir en el marco del patrón macro de segregación Norte/Sur. En cambio, las periferias occidentales y noroccidentales que se han estudiado presentan un perfil socioeconómico entre bajo y medio-bajo y no están tan alejadas del centro metropolitano ampliado, de sus recursos y de los lugares de prestigio de la ciudad: no se trata de espacios marginales, aunque en su interior, a escala micro, hayan barrios que se pueden caracterizar como marginales. Así, se plantea la existencia de condiciones de posibilidad para el surgimiento de esta nueva urbanidad periférica. Además de las características socioeconómicas generales que se acaban de mencionar, se supone que estas condiciones de posibilidad tienen que ver con nuevas estrategias de inversión en las periferias populares. A continuación, se trata de las lógicas de las nuevas inversiones.

\section{NUEVAS ESTRATEGIAS DE INVERSIÓN EN LAS PERIFERIAS POPULARES}

\section{1. La inversión pública y sus finalidades múltiples}

Una primera condición de posibilidad del nuevo modelo de urbanidad periférica es el incremento de las inversiones públicas, que se dio en nuestras zonas de estudio a partir de la mitad de los años 1990.

En barrios físicamente consolidados y jurídicamente legalizados, estas inversiones públicas permitieron en un primer momento dotar y equipar los barrios para alcanzar niveles de cobertura considerados como aceptables en comparación con el promedio de la ciudad. En este sentido, se puede afirmar que estas inversiones respondían a principios básicos de justicia compensatoria para desmarginalizar las periferias y «conectarlas» a la ciudad. En un segundo momento, las inversiones públicas se intensificaron y se orientaron con más fuerza hacia la esfera social. Así, bajo el mandato del alcalde Luis Eduardo Garzón (2004-2008), se construyeron 
38 megacolegios de más de 2000 alumnos, hospitales públicos, parques urbanos, etc. El hospital de Suba, administrado por la Secretaría Distrital de Salud, abrió sus puertas en 2006, mientras que el hospital del Tintal, que responde al mismo modelo de gestión, está por abrirse en 2012 a pesar de más de 2 años de retraso en la entrega. Esta segunda fase de inversión pública en las periferias contribuye a profundizar la integración de las periferias a la ciudad, una integración que la administración distrital ya no entiende solamente en términos físicos sino como el derecho a la ciudad, a sus recursos y por ende a un pleno reconocimiento social y político. El enfoque «de derechos», es decir el reconocimiento de los derechos de los ciudadanos (con mención especial al derecho a la ciudad) constituye desde la segunda mitad de 2000 un principio rector de la acción de la Alcaldía Mayor de Bogotá.

Si bien es importante reconocer el compromiso del Distrito con la mejora de las condiciones de vida de los habitantes de las periferias a partir de la implementación de políticas sectoriales, también es necesario identificar el papel que tuvieron las inversiones públicas en la atracción de un nuevo tipo de inversiones privadas. La definición de áreas de expansión urbana, la ampliación de la red de acueducto, la construcción de avenidas y la puesta en servicio del sistema de transporte masivo Transmilenio, ofrecieron condiciones óptimas para inversiones privadas de mayor escala en los lotes cercanos a los barrios de origen informal. En este sentido, el nuevo modelo de urbanidad periférica se puede interpretar como el resultado de una cierta alianza implícita, pero a veces formal como en el caso del Tintal, entre el Distrito de Bogotá y los grandes inversionistas y promotores privados para urbanizar los terrenos periféricos todavía no construidos.

Sin embargo, este proceso no ha sido pensado en el marco de una planeación urbana integral de las periferias. Los efectos urbanos y sociales no fueron anticipados ni tomados en cuenta por la administración distrital, que se dedicó a facilitar la urbanización de estas áreas pero no planteó el modelo de ciudad periférica que se busca construir. Aspectos como la concentración de poblaciones de bajos recursos en inmensos conjuntos de vivienda de interés social, la falta de calidad e identidad de los espacios producidos de manera masiva, la lejanía de los lugares de empleo, la valorización del suelo en los barrios más antiguos y sus posibles efectos excluyentes sobre los habitantes vulnerables no se discutieron. Por ejemplo, en el marco del Plan de Ordenamiento Territorial de Bogotá, se ha definido la Operación Estratégica Suba cuyo objetivo es el fortalecimiento de la centralidad urbana allí presente, para equilibrar la distribución de las actividades urbanas y mejorar el acceso a la ciudad de los habitantes de las periferias. El perímetro abarca los nuevos sectores centrales alrededor del Portal de Transmilenio y del centro comercial Plaza Imperial así como el núcleo fundacional y los costados de la avenida Suba entre estos dos polos. Pero, por considerar las centralidades urbanas como meras aglomeraciones de empleo y actividades económicas, la Secretaría Distrital de Planeación, contrató un estudio sobre el grado de ejecución («espontánea») de esta operación. Afirmó que esta operación estratégica se estaba cumpliendo sola, y que por lo tanto no se necesitaba intervenir en el marco de 
una planeación integral del área. No existen proyectos urbanos como tales para las periferias. Las inversiones distritales no presentan una dimensión territorial, se trata más bien de una suma de acciones sectoriales.

En este contexto, los inversionistas privados tienen un gran protagonismo en la producción de la nueva urbanidad periférica.

\section{2. Las condiciones de llegada de los grandes grupos inversionistas}

Las estrategias de inversión de los grandes grupos inmobiliarios privados en espacios hasta ahora caracterizados por la pobreza y la informalidad responden a lógicas tanto de orden global (transformación del capitalismo) como de orden local, específicas de Bogotá.

Estas estrategias de inversión son en primer lugar determinadas por el contexto macroeconómico mundial y nacional. A principios de 1990, cuando la política de apertura económica impulsó el proceso de internacionalización de la economía, el sector inmobiliario se perfiló como uno de los motores de la economía colombiana. El boom de la construcción se evidenció en proyectos inmobiliarios de gran envergadura, como Ciudad Salitre, y por un importante desarrollo en la construcción de centros comerciales de primera generación, a cargo de empresas privadas en ocasiones asociadas con el Estado (Müller, 1999). Pero el sector inmobiliario enfrentó una crisis profunda en los años 1995-2000, ocasionada por una demanda casi nula, derivada a su vez de la escasez de asignación de créditos, con lo cual la actividad inmobiliaria había decaído.

Por consiguiente, y para mitigar la crisis, muchas empresas decidieron invertir en vivienda de interés social, lo cual explica la importancia de la construcción de este tipo de vivienda después del año 2000; tal es el caso de los proyectos en el Tintal y en Suba, que habían sido suspendidos a finales de los años 1990. La recuperación económica (con tasas de crecimiento superiores a 4 \% por año entre 2004 y 2008) marcó una nueva fase de la internacionalización de la economía colombiana, que se evidenció en la transformación de modalidades de producción de los centros comerciales con la incursión de multinacionales de gran distribución, de negocios al por menor y su refuerzo a través de fusiones, de inversiones directas extranjeras, y de nuevas estrategias de mercadeo. Estas circunstancias, así como una normatividad que transfiere el riesgo de no rentabilidad de los centros comerciales a la administración y a las empresas comerciales y no a los promotores, explican la proliferación de los centros comerciales de segunda generación en los años 2000 (Suárez, 2009). En ese contexto de crecimiento, las empresas buscaban constantemente reinvertir su capital, asegurando su rotación para mantener las altas tasas de rentabilidad; dinámica que explica el aumento cuantitativo de inversiones, tanto en materia de vivienda como de centros comerciales.

Las inversiones en las periferias populares plantean problemas de solvencia de la clientela y de gestión de relaciones entre los grupos sociales. Al respecto, Bogotá presenta condiciones específicas que permitieron superar estos obstáculos, 
lo que marca diferencias respecto a dinámicas similares en otras metrópolis latinoamericanas (Paquette Vassali \& Yesquaz Sánchez, 2009): las transformaciones descritas se dieron porque existía en las zonas de estudio disponibilidad de terrenos, en un contexto de agotamiento de suelo urbano y de déficit de vivienda a nivel distrital. Esta situación propició inversiones en proyectos inmobiliarios de altas densidades poblacionales, en zonas con barrios autoconstruidos ya muy densos, formando así los «grandes» mercados populares que permiten compensar, para multinacionales como la francesa Carrefour o la chilena Falabella, la débil solvencia económica de los habitantes.

En efecto, ante la total ausencia de intervención estatal en la producción de vivienda de interés social 9 , esta se encuentra totalmente a cargo del sector privado, de tal manera que las empresas inmobiliarias necesitan grandes parcelas para producirla de manera masiva, tal y como lo señala la encargada de la gestión del suelo de los proyectos de vivienda de interés social de la empresa Constructora Bolívar:

«La vivienda social es imposible si no es masiva. Construir vivienda social es trabajar más por volumen y por rotación que por grandes utilidades. En las zonas de renovación urbana, puedes hacer «tope VIS〉 de 130 salarios mínimos de estrato 3, pero no puedes bajar a menos de 50-60 millones (alrededor de 20000 euros). Necesitamos comprar el $\mathrm{m}^{2}$ a un precio bajo y es imposible en el caso de terrenos de 1000-2000 $\mathrm{m}^{2}$ que no bajan a menos de 180000 pesos/m² (67 euros)».

Además, esas grandes parcelas solo pueden estar situadas en el perímetro urbano del Distrito o en las municipalidades limítrofes del suroccidente, donde los terrenos son más baratos. De no ser así, «la respuesta del mercado no se da», nos dice la encargada, quien continúa: «debo vender una ciudad, no puedo vender una isla en el campo». Para los constructores, dada la ausencia de un tren regional, los problemas de movilidad y la concentración del mercado de trabajo en Bogotá constituyen «grandes limitaciones a la expansión urbana en la Sabana», al menos para la vivienda social en donde la mayoría de los habitantes no están motorizados. Si los promotores disponen de vastas extensiones de terreno conectadas a las diferentes redes, poco importa el medio físico y social en el cual se insertan los proyectos, como lo confirma el consultor Miguel Tellez:

«En la medida en que un proyecto es de gran magnitud, puedes darle un carácter propio y además ese carácter se extiende a su alrededor. Fue así que CAFAM pudo construir la última Ciudadela CAFAM en Suba, al lado de los barrios de Lisboa y Berlín que son muy populares. CAFAM tenía una parcela mucho más extensa que los dos barrios juntos. Por eso la ciudadela tuvo un efecto positivo en esos barrios».

A su vez, los grandes proyectos de vivienda social localizados en los sectores de Suba-Pueblo y del Tintal, generaron dinámicas de valorización inmobiliaria,

9 En el marco del modelo neoliberal de producción de vivienda de interés social, el Estado entrega solamente subsidios a las familias que hacen la solicitud. Véase el artículo de Sara Roa Muñoz en este mismo número temático. 
fenómeno que parece ser más una consecuencia que un objetivo de las estrategias de los promotores inmobiliarios. Según la encargada de gestión de suelo de Constructora Bolívar:

«Nosotros no mezclamos los estratos, es el mercado el que lo hace. Contrariamente a lo que se hace en México, no se me ocurriría mezclar los estratos altos con los estratos bajos en la concepción de un proyecto, a menos que el proyecto sea muy grande y que yo pueda manejar los estratos y los diferentes tipos de vivienda localizándolos en cuadras diferentes, como en La Felicidad10. Pero la regla general es que a corto plazo no puede haber viviendas de 200 millones de pesos (cerca de 80000 euros) al lado de viviendas de interés social. Sin embargo, esto cambia con el tiempo. El Recreo era el fin del mundo hace 5 años. Solo veías VIP, VIP y VIP11. Pero el sector se consolidó gracias a un urbanismo de calidad; hay parques, colegios. Hoy empieza a entrar el mercado de la vivienda de 70 millones de pesos (27 000 euros), y eso le da un cierto carácter mixto. Si hubiese querido atraer el mercado de hoy hace algunos años, no hubiese obtenido respuesta. No puedes iniciar un proyecto proponiendo la mezcla. En Suba pasó lo mismo. Antes de 2005, solo había proyectos de vivienda social de 100 salarios mínimos (alrededor de 50 millones de pesos, o sea 20000 euros), y hoy, al lado, encuentras proyectos inmobiliarios de más de 100 millones de pesos, de estrato 3 ó 4 (alrededor de 40000 euros)».

En un segundo momento, cuando los sectores periféricos empezaron un proceso de densificación bajo el carácter de urbanización formal, llegaron inversiones comerciales, que contaron con otra condición esencial a este tipo de inversión: la presencia del sistema de transporte masivo Transmilenio, el cual atrae flujos de personas alrededor de las estaciones. Encontrándose excepcionalmente que los centros comerciales quieran «conquistar territorios» implantándose antes que la vivienda. Esta situación solo se dio recientemente en el caso del centro comercial Altavista, ubicado frente al portal de Transmilenio de Usme, una zona pobre y socialmente homogénea y en menor medida, en el caso del centro comercial Santafé que fue construido en 2005 antes de la consolidación de la zona Norte de la ciudad, la cual depende de la adopción del Plan Zonal del Norte. Sin embargo existe un precedente histórico muy conocido: el primer centro comercial de la ciudad, Unicentro (1976), fue construido por la empresa Pedro Gómez fuera de los límites del espacio construido en esa época e impulsó la urbanización del sector de Santa Bárbara, hoy en día, uno de los principales polos de actividades dentro del centro metropolitano ampliado.

10 Dentro del plan parcial de La Felicidad se están construyendo 17000 viviendas en 104 hectáreas, ubicadas en la localidad de Fontibón, al oeste de Ciudad Salitre. El proyecto del promotor Pedro Gómez tuvo un eco importante porque mezcla viviendas de estratos diferentes y contempla la construcción de un gran número de equipamientos: un parque urbano de 7 hectáreas, biblioteca, colegio y centro comercial. Información disponible en: www.felicidadciudadparque.com

11 Vivienda de Interés Prioritario. Se trata de las viviendas de más bajo costo, inferior a 70 salarios mínimos vigentes, es decir aproximadamente COP\$ 35 millones, o 15000 euros. 
La falta de parcelas urbanizables y la necesidad de invertir son también las razones que llevaron a las empresas de la gran distribución y a los promotores de centros comerciales a interesarse en las periferias. Para el responsable del servicio de planeación de la empresa de promoción inmobiliaria Ospinas, promotora de los centros comerciales Plaza Imperial en Suba-Pueblo y Plaza Milenio en Patio Bonito:

«Es evidente que nos sentimos más tranquilos cuando hay un mayor poder adquisitivo. Pero las inversiones en las periferias funcionaron, así no sea fácil. La mayoría de nuestros negocios están ubicados en los barrios acomodados y nos encantaría hacer un centro comercial Andino12 tres veces más grande a dos calles de aquí - avenida 7a \# 79, es decir en los barrios más pudientes de la ciudad- o demoler un islote en el cruce de la Carrera Séptima con 72 para hacer un gran centro comercial. Pero la norma y los usos del suelo nos lo impiden. Preferiríamos mercados más maduros pero todas las ecuaciones no funcionan, entonces nos conformamos con los mercados grandes y le apostamos a su futura maduración. En Suba, alrededor del centro comercial Plaza Imperial hay cada día más gente y los ingresos son cada vez más altos. El mercado de Suba sigue madurando».

La expectativa de maduración de los mercados periféricos es la clave para los inversionistas que han asumido el reto de penetrar los mercados populares. Para cumplir sus objetivos, han elaborado diversas estrategias con el fin de superar los obstáculos relacionados entre otros con la baja solvencia económica, los problemas de seguridad y de convivencia. Por ejemplo, la directora de la expansión de Carrefour-Colombia nos explicó que a principios de los años 2000 se había llevado a cabo una reflexión para «llegar a ese tipo de mercado»:

«Nos basamos en los estudios del BID y de la ONU que buscan cómo incluir económicamente a la población situada en la base de la pirámide y cómo hacer negocio con los pobres ${ }^{13}$. Hay que tomar en cuenta que los pobres tienen un tipo de consumo diferente, por ejemplo no compran lo mismo cada mes ya que sus ingresos son diarios. Sin embargo son consumidores. Las personas de bajos recursos también necesitan comer y vestirse y a veces sacrifican muchas cosas para comprarse un televisor de pantalla plana. [...] Nuestro objetivo es ser más competitivos que la tienda de la esquina. Para lograrlo empezamos una batalla para ofrecer los precios más bajos. En Colombia, desarrollamos un formato de almacén especial para poder entrar en los mercados populares. El prototipo es Tintalito, en el centro comercial Plaza Milenio, cerca del Portal de Transmilenio Las Américas: es un almacén más pequeño con un abastecimiento más básico. Tiene los mismos proveedores y propone los mismos productos, pero hay menos productos importados y los acondicionamientos son diferentes, en

12 El centro comercial Andino está ubicado en una zona exclusiva de la ciudad y constituye un símbolo de centro comercial para clientelas adineradas.

13 Enfoque dominante en las instituciones internacionales a partir de fines de los años 1990, inspirado entre otros por los trabajos de Amartya Sen y Hernando de Soto. 
muy pequeña cantidad o al contrario en gran cantidad, como una bolsa de arroz de $10 \mathrm{~kg}$. Tratamos también de desarrollar el acceso al crédito. La idea del grupo es democratizar el consumo».

Conjuntamente a las estrategias comerciales, el grupo Carrefour invirtió fuertemente en las relaciones con la comunidad (programas de responsabilidad social) y en la seguridad de los almacenes. Según el director nacional de la seguridad de Carrefour-Colombia, un coronel retirado, «trabajar la manera en la que el Grupo entra en la comunidad» garantiza una buena aceptabilidad del almacén en los sectores populares y de esta manera contribuye a su seguridad. En Colombia, el $1 \%$ del total de ventas se reinvierte en seguridad y esto aparentemente da buenos resultados porque se presentan pocos hurtos en comparación con la situación en otros países del mundo donde está la multinacional.

Además, la estrategia principal de los promotores de los centros comerciales consiste en adaptar las características arquitectónicas al nivel socioeconómico del entorno urbano. Por ejemplo, el responsable de planeación de la empresa Ospinas nos explica que, a diferencia de los centros comerciales situados en los barrios de nivel socioeconómico superior, el centro comercial Plaza Milenio ubicado en el sector de Patio Bonito (que no «maduró» tanto como el sector de Suba-Pueblo) se concibió para ser limpio y agradable, «de facciones Ospinas», pero también para «dar el mensaje que el centro comercial es barato»: no hay decoración, ni arabescos en el piso y tiene solamente una escalera eléctrica. Menciona también otra estrategia utilizada casi sistemáticamente por los promotores de los centros comerciales:

«Cuando llegamos a un lugar, procuramos reservar terrenos para la construcción de vivienda. En el Plaza Milenio, habíamos reservado 1000 viviendas que ya se construyeron. En Suba, habíamos guardado una parcela detrás del centro comercial Plaza Imperial para construir 1800 viviendas. Por ahora la mantenemos ahí porque estamos esperando que el centro comercial haga madurar la zona para construir vivienda de mejor estatus. Queremos que sea el proyecto inmobiliario de más alto nivel de toda la zona, con los mejores edificios y los mejores clubes. El centro comercial Plaza Imperial cambió la vocación de la zona que ya no es de vivienda social sino para vivienda de estrato 4».

De esta manera, los promotores de los centros comerciales captan una parte de la valorización que contribuyeron a generar en la zona, ya que el conjunto de inversiones, públicas o privadas, realizadas en una zona, constituye luego un fuerte argumento de venta para proyectos de estatus más alto. Por ejemplo, mientras que el centro comercial Santafé abrió sus puertas en 2006, este último tipo de proyecto inmobiliario estaba a la venta en 2009 cuando efectuamos el trabajo de campo. El proyecto Pijao de torres de 19 pisos hizo parte de la estrategia de los promotores del centro comercial Santafé desde el inicio, buscando aprovechar la maduración de la zona construyendo en un segundo tiempo vivienda de estatus más alto. El plano (fig. 5) es revelador en cuanto a las representaciones del nuevo orden espacial que se construye en las periferias, gracias a las nuevas proximidades 


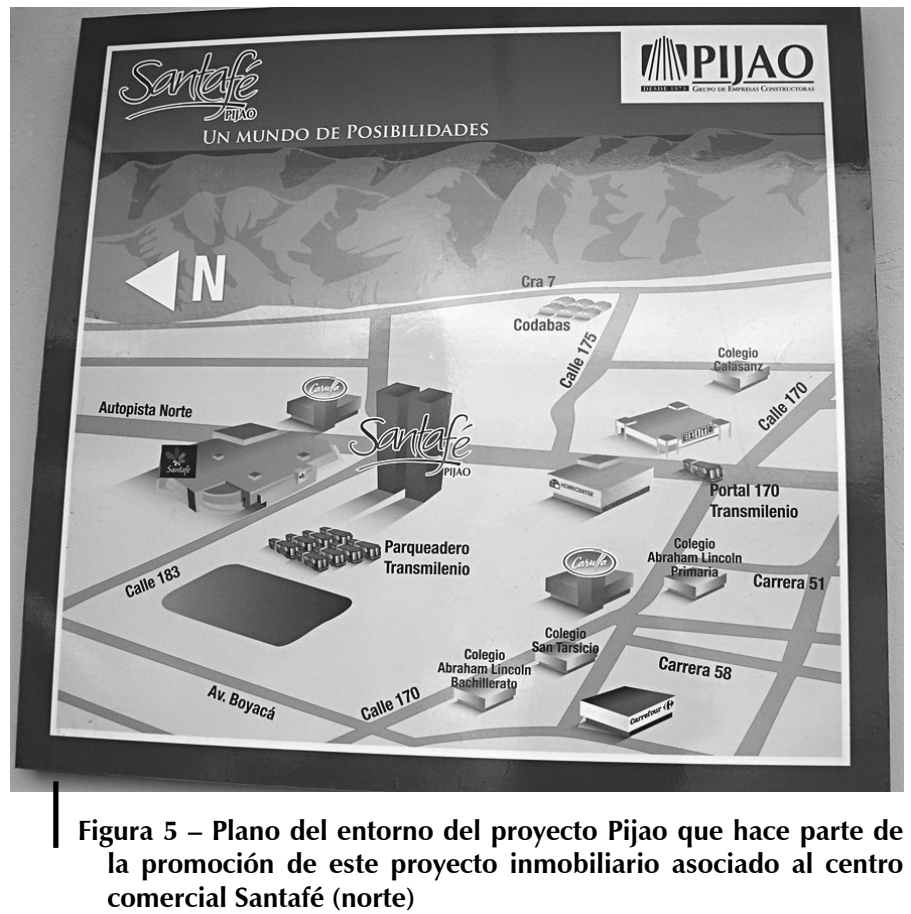

Foto: Alice Beuf (2009)

entre los centros comerciales, los nuevos proyectos inmobiliarios y el Transmilenio. En el caso de la zona Norte, se mencionan los colegios privados de la elite, que constituyen un factor de peso en las decisiones de los nuevos habitantes de la zona y por lo tanto, estos colegios se integran a las representaciones de la nueva urbanidad periférica para clases medias: representaciones que ocultan totalmente los barrios de origen informal ubicados en las laderas de los cerros orientales y que no figuran en el plano.

Es interesante notar que los proyectos mencionan sistemáticamente la presencia del Transmilenio y de los grandes almacenes-ancla de los centros comerciales: Éxito, Carrefour, Plaza Imperial, Home Center, Falabella. La cartografía asociada constituye un indicador significativo de las representaciones que se han construido alrededor de los nuevos sectores centrales de las periferias, particularmente en Suba-Pueblo, en la zona Norte y en el Tintal, mucho más que en Patio Bonito.

Como resultado de la crisis en el sector de la construcción y para satisfacer la prodigiosa demanda de vivienda de bajo costo (de interés social y para las clases medias bajas), las grandes constructoras empezaron a invertir en las periferias populares durante la década de 1990. Mientras los primeros habitantes tuvieron que luchar y pagar por el equipamiento de sus barrios, los inversionistas privados solo se arriesgaron en estos espacios después de que fueron legalizados, mínimamente equipados y en vía de consolidación avanzada, gracias a los esfuerzos 
de los residentes y a la apertura por parte del distrito de los ejes principales de transporte: nuevas avenidas y Transmilenio. Consecuentemente, se observan profundas mutaciones en los mecanismos de producción de las periferias urbanas. $\mathrm{Si}$ bien hasta entonces eran percibidos como espacios marginales, urbanizados de manera «pirata» y habitados por poblaciones pobres que tenían que soportar las numerosas injusticias causadas por una ciudad profundamente desigual, las periferias occidentales y noroccidentales de Bogotá se convirtieron, para los grandes inversionistas de la ciudad, en espacios con expectativa de desarrollo. El soporte del nuevo modelo de urbanidad periférica lo constituye la importante transferencia de renta, desde las comunidades y el sector público, hacia las grandes firmas privadas (de la construcción, la distribución y el sector financiero). El análisis de las estrategias de inversión de los grandes grupos privados permite destacar un modelo de conquista de estos espacios para las clases medias. Este modelo se fundamenta en una alianza entre los constructores de viviendas y los promotores de centros comerciales, que en Bogotá venden sus productos inmobiliarios una vez construidos (es decir que después los promotores no gestionan los centros comerciales y no tienen que asumir los riesgos asociados a su no rentabilidad, al contrario de lo que ocurre en muchos países latinoamericanos). Tanto los constructores de viviendas como los promotores de centros comerciales buscaron aprovechar las inversiones públicas en materia de espacios públicos y transporte para revertir las representaciones de estos espacios y atraer familias con un perfil social superior.

La nueva urbanidad periférica se puede interpretar como una estrategia de los inversionistas que tiene una dimensión principalmente inmobiliaria, pero que apuesta también a la adecuación de los patrones de consumo de los sectores populares con los de los sectores de clase media a partir de 2 mecanismos: la atracción de nuevos residentes de estatus social superior y la penetración paulatina de los mercados populares sustentada por el efecto de masa. Así, en los barrios autoconstruidos con altísimas densidades de población, el consumo sigue siendo bajo a nivel individual, pero es importante a nivel colectivo, lo cual asegura la rentabilidad de los desarrollos comerciales y el dinamismo de las centralidades populares que se refuerzan dentro de los barrios autoconstruidos. De esta manera llegaron a las periferias populares las dinámicas socioculturales asociadas al consumo masivo.

\section{3. Los inversionistas barriales: diversidad y éxito de algunos}

Como ya se mencionó, las transformaciones de las periferias populares no corresponden solamente a la masificación de la vivienda de interés social y a la proliferación de los centros comerciales. Han sido igualmente muy intensos los cambios sociales, económicos y físicos de los barrios autoconstruidos entre los años 1960-1990, es decir de los barrios de origen informal con algún grado de consolidación. Además de la densificación residencial que resulta en parte de la adición de pisos a las casas, las transformaciones de estos barrios se deben 
a la multiplicación de las actividades económicas y entonces al dinamismo de otras formas de inversiones privadas relacionadas con lo que se puede llamar de manera esquemática, las economías populares.

En estos espacios, que pasan actualmente por procesos intensos de diferenciación socioespacial interna, se pueden identificar diferentes tipos de actores económicos: grandes inversionistas, como las empresas multinacionales o las cadenas nacionales de gran alcance (por ejemplo, zapatos «Bucaramanga» o «Gasolina» siempre presentes en las centralidades populares de los barrios autoconstruidos) pero también empresas familiares provenientes de los sectores populares o del mismo barrio. Algunos se han ampliado considerablemente y se pueden proyectar en la metrópoli, el país o en el extranjero. Otros han crecido lo suficiente para alcanzar niveles de ingresos medios o medios-altos, como por ejemplo, panaderos que tienen una buena clientela, que han producido una inversión relativamente grande en materiales y que emplean a varias personas.

La entrevista realizada a un comerciante mayorista de materiales de construcción nos permite entender como algunos habitantes de los barrios populares han podido convertirse en verdaderos inversionistas que elaboran estrategias para desarrollar sus negocios fuera del mismo barrio. Conocedores de las economías populares, de sus lógicas, no padecen de la competencia de las multinacionales y otros grandes almacenes. Siguen creciendo, especializándose en servicios y productos que no ofrecen los hipermercados. Saben aprovechar de la gran ventaja que les da la relación construida en el tiempo con las comunidades de los barrios. Más allá del sector de la construcción, dinámicas similares pueden ser observadas también en la confección y venta de ropa. Se reproduce a continuación la entrevista en su integralidad:

«Yo soy de una familia bogotana, nativo de Chapinero. Mi padre tenía un taller y mi madre era ama de casa. Éramos 11 hermanos y le tocó a cada uno buscar su trabajo por su lado. Después de haber vivido en Las Ferias, Santa Lucía y en el barrio Gaitan, llegamos con mi esposa en 1971 al barrio Japón. Un familiar había comprado un lote y nos quedamos viviendo allí. En la época, yo era militar pero no me gustaba ser subalterno. Me retiré del Ejército en 1977 para establecerme como independiente. Después de algunos años trabajando como contratista en el sector de la construcción, decidí abrir un negocio propio. Pensaba en el inicio abrir un almacén de víveres, un comercio mayorista de huevos o de panela. Siempre quise ser mayorista. Intenté un primer negocio de mayorista de cerveza pero me cansé, porque los clientes llamaban hasta por la noche, esta vida no era saludable. Dejé y me fui por la ferretería, en 1979. Desde luego, poco a poco, crecimos. Empezamos con una carretilla, luego con un caballo, luego con un camión, luego otro camión, etc. El inicio de nuestro negocio fue una etapa muy próspera debido al crecimiento fuerte del sector: habían muchas construcciones, muchas autoconstrucciones. En 1986, construimos la bodega actual, al lado de nuestra casa. Ahora ya no vivimos en el barrio, es solo para el trabajo. Arrendamos la casa y nos 
fuimos a vivir en Colina Campestre en una casa en un conjunto cerrado (un sector de clase media alta).

La crisis económica que siguió la apertura económica, bajo la presidencia de Cesar Gaviria, se sintió de manera muy fuerte. Se tocó el fondo, pero nunca pensamos cerrar. Eso sí, pensamos en otras alternativas de negocios. Pero finalmente pudimos superar la crisis, adaptándonos al nuevo contexto económico. Bajó la autoconstrucción, así que tuvimos que diversificar nuestro portafolio de productos. En cambio, la llegada de Home Center no nos ha afectado, porque nosotros tenemos ventajas sobre Home Center. Nosotros podemos vender una puntilla y Home Center no. Allá para un cambio de material, le pueden causar problemas. Acá no, solo hablan conmigo y eso le gusta al cliente. Tenemos ventajas en términos de la relación al cliente. También tenemos servicio a domicilio. Para mi, estos mercados - los mercados de tiendas que son nuestros clientes- nunca se van a acabar. Incluso con la VIS, porque no la entregan completa; se tiene que hacer arreglos, incluso por cuestión de comodidad en viviendas terminadas. Mi deseo es crecer de manera formal para atender clientes informales, los que no pagan con tarjeta de crédito sino que llegan con sus pesitos y compran de una. Ahora, atendemos a clientes de todo Bogotá, hasta desde afuera, desde los pueblitos. Nosotros vamos a seminarios, a ferias del hogar, de la construcción, para estar a la vanguardia. Mañana hay un congreso de la construcción en Cartagena. Voy a ir, nos toca estar allá.

El futuro de este negocio, lo veo grande, veo grandes volúmenes. Ahora tenemos veinte y pico empleados, entre esta sede y las demás que tenemos en todo Bogotá. Tal vez nos trasladamos, entre Cota-Chía-Zipaquirá. Estamos por comprar un lote allá y hacer un hipermercado. Cambiaríamos la forma, no la estructura. Pero no abandonaríamos el punto del Japón, por supuesto. Solo ya no vamos a sacar camiones desde acá, sería mejor sostener esta bodega solo con un carrito pequeño. Por cuestión de logística, tenemos que reorganizarnos. Pero aquí es el eje de todo.

Suba es mi punto de partida. Es el sector que ha crecido conmigo. Cualquier vecino que va a entrevistar que me conoce, le va a decir: 〈él es el dueño del barrio, del Japón de Subà. Seguimos teniendo buenas relaciones con los vecinos, con los de mi generación. El problema son las personas nuevas. Por eso nos fuimos a vivir en Colina Campestre, por cuestiones de seguridad, porque la gente se imagina que uno anda con montón de dinero».

Los ejemplos de éxito de algunos inversionistas provenientes de los sectores populares no deben ocultar sin embargo el hecho de que la gran mayoría de los actores económicos presentes en los barrios de origen informal apuestan al sostenimiento de una actividad comercial como estrategia de supervivencia. Frente a un desempleo masivo y al deterioro de las condiciones de trabajo en el sector formal, muchos prefieren «rebuscarse» o abrir una tienda en el primer piso de su casa para sacar algunos ingresos, muy variables. En este sentido, los tenderos forman una gran proporción de los trabajadores independientes de 
las periferias populares, en los barrios de origen informal pero también en los conjuntos formales de vivienda de interés social.

\section{A MANERA DE CONCLUSIÓN}

Este artículo desarrolla una interpretación de las transformaciones de las periferias populares a partir de una propuesta analítica, la del surgimiento de un nuevo modelo de urbanidad periférica, y de un enfoque específico, la producción de los espacios periféricos y sus relaciones con las formas de movilización social y política. Se muestra la introducción de un modo de producción «desde arriba» en espacios tradicionalmente producidos «desde abajo»: las acciones resultantes de grandes inversiones, públicas y privadas, tienen cada vez más importancia. Uno de los motores de este incremento de inversiones es sin lugar a dudas la integración de los sectores populares — más no marginales_ a la sociedad del consumo.

Estos procesos conllevan, entre otros, una recomposición de las pautas de la segregación socioespacial y generan nuevas desigualdades dentro de las mismas periferias, en parte por los fenómenos asociados a la valorización del suelo. La complejización de los procesos de producción de las periferias populares cambia en profundidad las formas de relacionarse con los espacios urbanos. En parte debido a estos procesos (y en otra parte debido a elementos más coyunturales como la política de participación del Distrito), las movilizaciones sociales y políticas evolucionan.

También cambian las formas de habitar de las periferias, y es una dimensión que no se ha podido abordar acá. En el modelo anterior, para las familias de clase popular y de media-baja, el acceso a la propiedad en los espacios periféricos urbanísticamente deficientes podía ser valorizado como una garantía de seguridad material a pesar de que la vivienda no presente las calidades esperadas. Lo que se observa con más frecuencia hoy es que las periferias para ciertas familias, al igual que para los grandes grupos inversionistas, se vuelven espacios de inversión financiera: compran un apartamento con crédito hipotecario a la espera que este se valorice para comprar otro más tarde en una «mejor» zona de la ciudad. Eso sí, no comentan lo que van a hacer si simultáneamente los precios inmobiliarios suben en toda la ciudad, lo que está sucediendo actualmente en Bogotá. En este sentido, es pertinente preguntarse si las nuevas modalidades de producción de los espacios periféricos producen lugares para hacer crecer su capital, o lugares para vivir.

\section{Referencias citadas}

ABRAMO, P., 2003 - La teoría económica de la favela: cuatro notas sobre la localización residencial de los pobres y el mercado inmobiliario informal. Ciudad y territorios: Estudios territoriales, Vol. XXXV, n. ${ }^{\circ}$ 136-137: 273-294; Madrid: Ministerio de Fomento. 
De las luchas urbanas a las grandes inversiones. La nueva urbanidad periférica en Bogotá

ARDILA, G. (ed.), 2003 - Territorio y Sociedad: el caso del Plan de Ordenamiento Territorial de la ciudad de Bogotá, 612 pp.; Bogotá: Ministerio de Medio Ambiente, Universidad Nacional de Colombia, Red de Estudios de Espacio y Territorio.

BERRY-CHIKHAOUI, I., \& DEBOULET, A., 2000 - Les compétences des citadins dans le Monde arabe. Penser, faire et transformer la ville, 406 pp.; París: Karthala.

BEUF, A., 2011 - Nuevas centralidades y acceso a la ciudad en las periferias bogotanas. Bulletin de l'Institut Français d'Études Andines, 40 (1): 147-178; Lima.

CAPRON, G. (ed.), 2006 - Quand la ville se ferme. Quartiers résidentiels sécurisés, 288 pp.; París: Bréal.

DAVIS, M., 2006 - Planet of Slums, 228 pp.; London-New York: Verso.

DUHAU, E. \& JACQUIN, C., 2008 - Les ensembles de logement géants de Mexico. Nouvelles formes de l'habitat social, cadres de vie et reformulations par les habitants. Autrepart, Vol. 3, n. ${ }^{\circ}$ 47: 169-185.

DUREAU, F., 2000 - Les nouvelles échelles de la ségrégation à Bogotá. In: Métropoles en mouvement. Une comparaison internationale (F. Dureau, V. Dupont, E. Lelièvre, J. P. Levy \& T. Lulle, eds.): 247-256; París: Anthropos, IRD.

FIX, M., ARANTES, P. \& TANAK, G., 2003 - The case of São Paulo, Brazil. In: Understanding Slums: Case Studies for the Global Report; São Paulo: ONU-HABITAT, UCL-DPU.

JANOSCHKA, M., 2002 - El nuevo modelo de la ciudad latinoamericana: fragmentación y privatización. EURE, Vol. 28, n. ${ }^{\circ}$ 85: 11-30.

JARAMILLO, S., 2008 - Reflexiones sobre la «informalidad» fundiaria como peculiaridad de los mercados de suelo en las ciudades de América latina. Territorios, 18-19: 11-53.

MÜLLER, J. M., 1999 - Grandes centros comerciales y recreacionales en Santafé de Bogotá: Origen, características y tendencias de desarrollo. Revista Perspectiva Geográfica, n. ${ }^{\circ}$ 3: $48-87$.

ORDOÑEZ MONTOYA, F., 1992 - El barrio del Rincón-Escuela en Suba, proceso de formación y formás organizativas; Bogotá: Universidad Santo Tomás. Tesis de fin de estudios.

PAQUETTE VASSALI, C. \& YESQUAZ SÁNCHEZ, M., 2009 - Producción masiva de vivienda en Ciudad de México: dos políticas en debate. Centro-h, Revista de la Organización Latinoamericana y del Caribe de Centros Históricos, n. ${ }^{\circ}$ 3: 15-26.

PINEDA, B. C. (ed.), 1998 - Bogotá, historia común: menciones de honor. Il Concurso de Historias Barriales y Veredales, 261 pp.; Bogotá: Acción Comunal Distrital.

SAGLIO-YATZIMIRSKY, M. C., 2002 - Intouchable Bombay: le bidonville des travailleurs du cuir, 326 pp.; París: CNRS.

SUÁREZ, M., 2009 - La proliferación de centros comerciales en Bogotá. Colombia; Santiago de Chile: Universidad de Chile. Tesis de Maestría en Geografía.

UNITED NATIONS HUMAN SETTLEMENTS PROGRAM, 2003 - The challenge of Slums, Global Report on Human Settlements, 344 pp.; London: UN-Habitat, Earthscan Publications Ltd London and Sterling, VA.

VALLADARES, L., 2000 - Qu'est-ce qu'une favela. Cahiers des Amériques Latines, $\mathbf{n} .^{\circ}$ 34: 61-72. 